\title{
Mobility constraints, productivity trends, and extended crises
}

\author{
Domenico Delli Gatti a , Mauro Gallegati ${ }^{\mathrm{b}, *}$, Bruce C. Greenwald ${ }^{\mathrm{c}}$, Alberto Russo ${ }^{\mathrm{b}}$, \\ Joseph E. Stiglitz ${ }^{\mathrm{c}}$ \\ a Università Cattolica, Milano, Italy \\ b Università Politecnica delle Marche, Ancona, Italy \\ c Columbia University, New York, United States
}

\section{A R T I C L E I N F O}

\section{Article history:}

Received 15 June 2011

Received in revised form 4 March 2012

Accepted 16 March 2012

Available online 28 March 2012

\section{JEL classification:}

E24

N12

Keywords:

Crisis

Sectoral imbalances

Productivity

\begin{abstract}
A B S T R A C T
In this paper we propose an interpretation of the current Global Financial Crisis which emphasizes sectoral dislocation following localized technical change in the presence of barriers to labor mobility. This tale is reminiscent of a similar tale concerning the Great Depression. In the 30s technical change was localized in agriculture, where income fell because rising productivity could not be offset by a shrinking labor force due to the costs of moving out of agriculture for unemployed workers, inelastic demand for agricultural output meant that as output increased income declined. As individual incomes fell below the level necessary to finance the transition to manufacturing, excess labor became trapped in agriculture, reducing wages and exacerbating the rise in output. Shrinking incomes in agriculture reverberated on the other sectors, mainly manufacturing causing a large depression. Nowadays, it is manufacturing that plays the role of epicenter of technical change. Falling incomes in manufacturing yield a lack of demand for goods produced in the rest of the economy, namely the service sector. This may be the deep rooted cause of the long lasting slump and the painfully slow recovery.
\end{abstract}

(c) 2012 Elsevier B.V. All rights reserved.

\section{Introduction}

Interpretations of the global financial and economic dislocations that began in late 2007 have focused largely on traditional causes. Unjustified optimism about asset prices and associated risks (primarily in housing but also in financial industry equities and even in equities generally), accommodated by lax regulation, careless private lending and loose monetary policies led to unsustainable levels of household and financial leverage. The inevitable collapse of the underlying asset prices then caused widespread bankruptcies, foreclosures and impaired balance sheets among households, firms and financial institutions. Combined with consequent large increases in the incremental risks of lending and investing, these balance sheet effects induced large declines in household spending, firm output and investment spending, and bank lending. ${ }^{1}$ Asymmetric information concerns have ruled out many natural financial market recapitalizations like extensive new equity issues or debtequity swaps, most of which are in any case not available to individual households (again for informational reasons). ${ }^{2}$ Thus,

\footnotetext{
* Corresponding author. Tel.: +39 0712207088; fax: +390712207102.

E-mail address: mauro.gallegati@univpm.it (M. Gallegati).

1 The underlying theory describing this was set out several years before the crisis in Greenwald and Stiglitz (1993) based on their work in the 1980s. See also Bernanke et al. (1999) on the working of the financial accelerator in an asymmetric information framework.

2 Proposals to force restructurings have been rejected by Congress, and attempts to induce restructurings voluntarily by the Administration have largely failed. Stiglitz (2010) notes that one of the reasons for these failures is that banks would be forced to recognize losses on their balance sheets, with the result that they would have to raise additional capital. Changes in accounting standards in April 2009 allowed banks to keep even impaired mortgages on their books as if they would be fully repaid, in a switch from mark-to-market accounting to what he refers to as mark-to-hopeäccounting.
} 
household and company balance sheets have been restored only slowly over time through accumulated savings and debt reductions associated with gradual declines in real asset holdings by means of inventory liquidations and gross investment levels below depreciation. Some form of this asset-based cycle is the currently accepted conventional wisdom about the present crisis (Adrian and Shin, 2008; Shiller, 2008; Demyanyk and Van Hemert, 2010).

However, there are reasons to believe that this time things are indeed different, although by no means unprecedented. ${ }^{3}$ The depth and duration of the present crisis is outside the normal range of post-World-War-II experience. And, it is far from clear that the crisis is over, despite fiscal and monetary interventions that have also been without precedent in the post-War era (and even the pre-War period). Most projections suggest that it will be years before unemployment returns to "normal" levels. Moreover, in some countries-notably Japan-the current crisis comes on top of decades of poor-macroeconomic performance that cumulatively appears to have had effects that are comparable to those experienced in the Great Depression. Not surprisingly, therefore, references to and renewed interest in the Great Depression have featured prominently in the literature on the current crisis (Temin, 2010).

This paper presents a model of an extended structural crisis operating within the framework of an asset-based cycle that both accounts for many hitherto unexplained aspects of the entry into and recovery from the Great Depression, and illuminates the role of structural factors in the present crisis. It highlights the interactions between cyclical factors and structural factors, and explains why well-designed Keynesian responses may be appropriate even when there is a structural aspect to the underlying crisis. This stands in marked contrast to those who are now claiming that most of the remaining unemployment is structural-there is a new "normal" to which we must now accommodate ourselves-and therefore policies designed to stimulate the economy may not only be useless, they may be counterproductive.

Our analysis has at its root a model of persistent dislocation across sectors of a heterogeneous economy. In essence, persistent structural problems arise when a large but distinctive sector of a multi-sector economy experiences a major decline in economic importance-prices, revenues and potential employment. Most often this decline is associated with rapid but uneven productivity growth in the face of inelastic, relatively more slowly growing sectoral demand. In theory-at least in neoclassical theory focusing on a frictionless world-rapid productivity growth should lead to greatly reduced employment in the sector in question, migration of labor to other sectors and overall high levels of economic growth. But, if high productivity growth induces unexpected declines in earnings in this sector and if workers in the sector have most or all of their capital invested locally or there is not enough human capital for migrating toward a new sector, then the workers who must migrate may be sufficiently impoverished that they cannot cover the required fixed costs of migration and retraining. ${ }^{4}$ These fixed costs will be larger, of course, if the sector experiencing the shock is geographically isolated or entails skills that are different from the sectors to which it would like to migrate.

The immobilization of labor in the dying (but now high-productivity) sector means lower overall sectoral income and a consequent reduction in the demand for the output of other sectors. Participants in those other sectors do benefit from lower prices from the impoverished sector. But, if the effects of these rising real incomes on other sector demand are smaller than the more concentrated effects of declining income in the impoverished sector-and there are many reasons why this should be so-then overall demand for other sectors' output will decline. The result will be a prolonged slump in overall aggregate demand until significant migration out of the impoverished sector can occur. This slump will, in turn, further interfere with such out-migration since employment opportunities in the other sectors will necessarily be limited. Direct cost related barriers-to-migration will be reinforced by coordination problems associated with creating jobs in the other sectors. Migrants from the impoverished sector cannot move to jobs that are not available. Short-term balance sheet adjustments in these other sectors in response to declining demand reinforce the problem of job creation.

\section{An incomplete explanation for the crisis and the great recession}

Understanding the nature of the crisis-and why the economy has remained weak-is essential not only for interpreting the events of the past few years, but for ascertaining prospects and assessing policies going forward.

Initial assessments and policy interventions have focused on the role of the leveraged financial sector, and the subprime spark. Furthermore, recoveries from financial crises, it is said, are slow, partially because bank and firm balance sheets recover only slowly. ${ }^{5}$ Financial crises are typically associated with the destruction of information, e.g. about who is creditworthy, as banks are pushed into bankruptcy (Greenwald and Stiglitz, 2003). In contrast to the policies pushed by the IMF and the US Treasury in Indonesia and elsewhere during the East Asia crisis, we congratulate ourselves in having preserved these institutions, admittedly at some risk of moral hazard going forward. But there is still the slow process of rebuilding bank balance sheets.

\footnotetext{
3 For some alternative interpretations, see Krugman (2009), Mulligan (2009), Reinhart and Rogoff (2009), Taylor (2009), and Barro and Ursua (2010). As in Greenwald and Stiglitz (2003), several of these authors note that a recovery from a financial crisis may be prolonged, far slower than a "normal" recession-which is a result of excess inventory accumulation or monetary authorities stepping on the brakes too hard-because of the long time that it takes to rebuild bank balance sheets.

4 On the role of mobility costs in the growth of service sectors vs. goods sectors, see Lee and Wolpin (2006).

5 See, e.g. Reinhart and Rogoff (2009). The theory is set forth, e.g. in Greenwald and Stiglitz (1993).
} 
But, the failure of the strategies undertaken to end the crisis hints at the incompleteness of the diagnosis that informed them. Since the crisis was deemed to be a financial one, lawmakers and central bankers crafted policy on the assumption that if the financial system were repaired, the economy would return to health. This gave a sense of priorities to government. It provided justification for the bank bailout, and TARP; political leaders supporting this highly unpopular bailout could feel virtuous because they put the well-being of the economy over pursuing short-term political advantage. With a quick repair of the financial system in the offing, only a short-term stimulus was required to tide the economy over.

The weaknesses in the economy have, however, turned out to be more persistent than this diagnosis would have suggested; the Fed has (as of early 2012) committed itself to leaving interest rates at near zero through the end of 2014. Though there are still many concerns with the financial system (lack of transparency, inadequate SME lending, weaknesses in many local and regional banks), it is not apparent that finance is holding the economy back. (Of course, in any crisis, the real and financial sectors are intertwined: any real crisis, lasting long enough, will have consequences for the financial sector; and the subsequent weaknesses in the financial sector will have real consequences. That is why ascertaining causality is always going to be difficult. ${ }^{6}$ )

If the financial sector were the cause of the economy's current problems, it should be reflected most strongly in investment. But business investment in the United States, as a percentage of GDP, is not particularly low-certainly not in a way that would be suggested if the availability of funds were the binding constraint. Indeed, large businesses are reportedly awash with cash. ${ }^{7}$

Of course, investment in real estate is constrained-less than half the pre-crisis level, but, with real estate prices down 30-40 percent, that would presumably be the case even with perfectly functioning financial markets. Indeed, the excessive investment in real estate was really a symptom of a dysfunctional financial market; one can hardly complain about a market that finally begins to show some sense of "rationality" after a prolonged period of excess.

There is another reason for suspecting that finance is not the major constraint in the economy's recovery-and therefore not the only explanation for its weakness. If the financial sector were really broken, real lending rates would presumably be very high. With inflation around 2 percent, real T-bill rates are now markedly negative, and even prime lending rates are very low (adjusted for inflation, a little over 1 percent). ${ }^{8}$ This is in marked contrast to the Great Depression, in which prices were falling at 10 percent a year, so real interest rates were, in fact, very high. Indeed, the low (negative) real interest rates raise questions about conventional monetary theory and policy, which focus on real interest rates. Some economists have even suggested that the limitation of monetary policy in restoring the economy is the "zero lower bound," and some (such as Krugman $^{9}$ ) have made reference to a (Keynesian) "liquidity trap." With real interest rates already negative, it is hard to believe that high interest rates are keeping the economy from recovering, and the data on investment cited earlier is consistent with this perspective. It is hard to argue that with these low real interest rates, finance is the critical constraint. ${ }^{10}$

Another aspect of the conventional wisdom is that if the economy is to recover, households must deleverage. The fact that the process of deleveraging is so slow-in the absence of some process of debt restructuring-adds pessimism about the economy's prospect. There is no doubt that the fact that nearly one out of four Americans with a mortgage is underwater (an aggregate gap between what is owed and the value of the underlying property estimated at some $\$ 700$ billion $^{11}$ )

\footnotetext{
${ }^{6}$ Financial sector problems arise both directly, as a result of a weak economy, and indirectly, as a result of government responses to the fear of a weak economy. Governments may respond to what otherwise would be a weak economy by lowering interest rates and weakening regulation, or undertaking other policies that help create future financial crises. Arguably, this was the case in the US.

7 Private non-residential fixed investment as a percentage of GDP was around 10.0 percent in the second quarter of 2011 , while the historical post-war average is 10.7 percent (though, we note that GDP has fallen below trend). Equipment and software investment by firms in real terms was about 8.2 percent of GDP in early 2011 compared to a high of 8.4 percent in 2007 and 6.6 percent at the peak of the crisis in the fourth quarter of 2008 . These investments, being difficult to collateralize, are the first to suffer when bank lending is restricted. Their relatively high level suggests that a shortage of bank lending has not had a significant dampening effect on business investment. Business investment in structures has fallen sharply but this appears to be due more to the overhang of empty buildings from the earlier boom than to limitations on bank lending. The level of commercial and industrial lending for small domestic banks rose in the second quarter of 2011 to 2nd quarter 2007 levels, after a prolonged period of being far lower. (Seasonally adjusted commercial and industrial loans at all commercial banks were $\$ 1.293$ trillion on August 1, 2011, and \$1.293 trillion on July 1, 2007, according to figures from the St. Louis Fed. Available at http://research.stlouisfed.org/fred2/categories/32389, accessed January 24, 2011.) The trend toward industrial firms holding more cash is not new. Bates et al. (2009) document between 1980 and 2006 a doubling in the average cash-to-assets ratio for US industrial firms, such that "at the end of the sample period, the average firm can retire all debt obligations with its cash holdings." They find (p. 2018) that the "main reasons for the increase in the cash ratio are that inventories have fallen, cash flow risk for firms has increased, capital expenditures have fallen, and R\&D expenditures have increased" (where cash flow risk is measured as the standard deviation of industry cash flow to assets). It may be that the post-crisis build-up in cash reflects increased uncertainty and the consequences of the extreme credit conditions of 2008, which many businesses fear may occur again.

8 Inflationary expectations, as reflected by TIPS, are also low. The average spread between TIPS and 10-year treasuries (a good measure of expected inflation) was about 2 percent from 2010 through the summer of 2011. The CPI increase between August 2010 and August 2011 (excluding food and energy) was also 2 percent (although the overall index including food and energy increased by 3.6 percent). Data from St. Louis Fed, available at http://research.stlouisfed.org/fred2/series/CPILFESL and http://research.stlouisfed.org/fred2/series/CPIAUCSL?cid=9.

9 Krugman (2009) and Eggertsson and Krugman (2010).

10 More accurately, it is hard to argue for this within the conventional models, in which credit rationing does not exist. Stiglitz and Weiss (1981) explain why there may be credit rationing, and Greenwald et al. (1984) explain why the extent of credit rationing may vary over the business cycle. But as we noted, the level of investment in equipment and software and the magnitude of cash holdings by large firms suggests that by mid 2011 finance was not the major constraint on recovery.

11 Moody's estimates that some 14 million homeowners are in positions of negative equity, "half by more than 30 percent ... (and) the average underwater homeowner's debt exceeds market value by nearly \$50,000" (Zandi, 2011, p. 2).
} 
causes anxiety and considerable misery among a substantial fraction of American citizens, and one can argue that it was unconscionable-and politically unwise-to ignore this, especially as money was shoveled to the big banks. Others hope that, somehow, even with the slow pace of deleveraging, the American consumer will return; they look carefully at the monthly sales data to see some indication that that might be the case.

A closer look at the data, however, suggests that deleveraging, as desirable as it might be from a welfare point of view, is not going to lead to significant increases in consumption-certainly not the basis of a strong recovery.

Sustaining near full-employment in countries like the United States prior to the crisis of 2008 seems to have depended on extraordinarily profligate consumer behavior. Under ordinary circumstances, a near zero savings rate like that of US households in the mid-2000s should have generated significant inflationary pressure. But in spite of the absence of inflationary pressures, the low savings rate was clearly unsustainable. High income households, with roughly 40 percent of permanent income, typically save 15 percent or more of their incomes. ${ }^{12}$ By themselves, they account for a 6 percent savings rate out of total income: 15 percent of 40 percent. An overall zero savings rate, therefore, required that middle and lower income households with 60 percent of permanent income dis-save at a rate of 6 percent of total income per year. This, in turn, meant that these households had to spend 110 percent of their incomes every year: -10 percent savings times 60 percent for -6 percent of total income. The return to a zero savings rate by middle and lower income households in the wake of the 2008 financial crisis, which eliminated their continuing ability to borrow, led to an increase in the overall savings rate to roughly 6 percent. ${ }^{13}$ The consequent decline in consumption demand appears to have been the proximate cause of the recession. (Housing demand began to decline in early 2006.) Continued prosperity pre-crisis seems to have depended on continued bubble-driven consumption. If a return to "normal" savings levels was inevitable, then the financial crisis affected the timing rather than existence of a severe recession. ${ }^{14}$ By the same token, "fixing" the financial system, or even deleveraging, is not likely to have a substantial, sustained effect on aggregate consumption, and therefore on aggregate demand. The savings of the bottom 80 percent are not likely again to be negative, and those of the upper 20 percent, are not likely to fall much below 15 percent. ${ }^{15,16}$

Looking at this and other crises around the world throws further doubt on the hypothesis that this is centrally a financial sector crisis. First, the severity of the downturn has generally been unrelated across countries to the financial origins of the crisis. The United States and the United Kingdom, both countries with outsized financial sectors that failed spectacularly in the wake of widespread financial misbehavior, suffered relatively less severe output declines than other nations with sounder financial systems and no notable failures of financial institutions. Finland, Japan, Germany, Denmark and Italy all suffered larger declines in GDP than the United States and the United Kingdom. In other countries-Spain, Ireland, Greece and Portugal-financial difficulties and banking insolvencies appeared late in the crises following severe real economic contractions. In these cases, financial crises appear to have been the consequence rather than the cause of the recession, though weak financial systems are more likely to be damaged by a "real" economic downturn, and the consequent financial crisis may serve to prolong the downturn. ${ }^{17}$

\footnotetext{
12 Dynan et al. (2004, pp. 399-400) find savings rates varying from zero for the lowest quintile of the income distribution to in excess of 25 percent for the top.

13 Personal savings rates were around 5 percent in 2009, before rising toward 6 percent in 2010. At the end of 2011, rates dropped back down to 3.5 percent, around what they were in 2004.

${ }^{14}$ The analysis of this paper does not deny the importance of the failings of the financial sector in determining not only the timing of the crisis, but also the depth and duration of the downturn. The legacy of excess investments in real estate and of excessive indebtedness by households is playing a role, just as-we argue below-the build-up of "forced savings" during World War II helped not just to prevent the US from sliding back into recession or worse, but to propel the country into a new prosperity.

${ }^{15}$ Deleveraging could have one important effect on aggregate demand: lower expenditures servicing debt would leave more money to spend on real goods-illustrating another way in which the excessive financialization of the economy may have contributed to its weaknesses. But the data suggests that this effect is likely, at most, to be small-perhaps because of the innovativeness of the financial sector in finding new ways of extracting money from consumers, partly because some of the deleveraging is taking the form of home foreclosures, forcing individuals into rental properties, which over the longer run may actually reduce what can be spent on other goods and services. Non-consumption household outlays, which include household interest payments fell from 3.94 percent of total outlays at the peak of the borrowing boom in 2007 to 3.45 percent at the end of 2010. The resulting increase in funds available for consumption was less than .5 percent, and this includes the impact of lower household interest rates as well as deleveraging.

${ }^{16}$ Once the deleveraging process is completed, the rate of growth of consumption might be restored to a more normal level. But full economic recovery, with a restoration of full employment, would require still more rapid growth.

${ }^{17}$ This data is only meant to be suggestive, because many factors contributed to the depth of the downturn and the speed of recovery (and there are alternative measures of the depth of the downturn-Germany had a larger downturn in output, but a smaller downturn in employment). Some countries (such as China) took strong actions to offset the downward pressures. Still, these experiences suggest that it is structural factors (the composition of output and trade dependence), as much as weaknesses in the financial sector, that determined the depth of the downturn. With the precipitous fall in trade, especially in manufactured goods, countries that were more dependent on exports of manufactured goods suffered more, ceteris paribus. To be sure, with weak banking systems, precipitous declines in GDP can translate into financial sector problems, making the challenge of recovery greater.

The evolution of the crisis has also thrown doubt on other shibboleths. A central contention of some central bankers (and many strands of macroeconomics) has been that it is wage rigidities which give rise to extended periods of unemployment. Yet, in this crisis, the United States, supposedly the advanced industrial country with the most flexible labor market, has been plagued with higher and more persistent unemployment (especially relative to the drop in GDP) than, say, Germany. This is consistent with both theoretical work (surveyed in Greenwald and Stiglitz, 1993) that argues against the hypothesis that it is wage and price rigidities that are primarily responsible for the magnitude of employment and output fluctuations (on the contrary, fluctuations may be greater with more flexible wages and prices) and with the confirming empirical studies (Easterly et al., 2001a, 2001b).
} 
Moreover, for all the talk of a "great moderation," the period since 1980 has been characterized by severe persistent crises outside the United States ${ }^{18}$ and, in many quarters, slow growth. ${ }^{19}$ Crises, in particular, have become far more frequent and more severe. What is striking is that this was in a period where economists claimed we knew more about economic management, and more countries followed the precepts advocated by economists. One explanation is that what was "learned" was wrong, and the policy advice was a move in the wrong direction. Another explanation (not necessarily mutually exclusive) was that there were real changes which lead even well-managed economies into crises, or at least increased the difficulties of economic management.

While in some of the crises, bubble-like behavior played a relatively minor role, Japan in the early 1990s did suffer from the collapse of a spectacular financial bubble and a badly impaired banking system. But by 2000 , these problems were in the past; yet stagnant economic growth continued. The generally disappointing rate of recovery from the crisis in many countries besides the US (with the important exception of the emerging markets) despite the marked improvement in the financial sectors in these countries, ${ }^{20}$ suggests that the Japanese experience may not be an isolated one.

The real changes in the economy that we believe are at the core of the problem of economic adjustment are those caused by the enormous increase in productivity in manufacturing. The issue has to be looked at, as we have noted, from a global perspective. While the increase in manufacturing productivity in excess of the increase in demand for manufactured goods will mean that the global manufacturing employment will decrease, there are, at the same time, shifting comparative advantages. ${ }^{21}$ Countries that both have a large manufacturing sector and are losing their comparative advantage will face the largest structural transformations-and thus may be the countries (ceteris paribus) most affected by the crisis.

Not surprisingly, because the cause of this downturn is different from that of other more recent recessions, it is plausible that the policy response might have to be different. There should be structural policies to facilitate the movement of labor that is "trapped" in a dying sector, and that requires understanding the economic forces that impede mobility. But even though structural policies are part of the solution, traditional Keynesian policies play a role. The corrective intervention that brought about the end of the Great Depression was World War II-but not as it is generally interpreted. As we explain, the policies were both Keynesian (a massive economic stimulus) and structural. Today, correcting this situation will require a focused effort in managing the transition of workers on a global basis out of manufacturing into services with an impact comparable to that of World War II in moving workers off the farm. Our analysis, which shows that well-designed Keynesian responses may be appropriate even when there is a structural aspect to the underlying crisis, stands in marked contrast to those who now claim that most of the remaining unemployment is structural-there is a new "normal" to which we must now accommodate ourselves-and therefore policies designed to stimulate the economy may not only be useless, they may be counterproductive.

\section{The Great Depression tale}

In the Great Depression, the high-productivity-growth impoverished sector was agriculture. Long-term increases in global farm productivity coupled with increases in land under cultivation had, since the second-half of the 19th century, led to long-term increases in farm output above the rate of increase of farm demand and, thus, secularly declining farm prices. Harvest and demand fluctuations meant that this trend was far from uniform and there were periods of high prices and farm prosperity. But by the late 1920s, farm prices were in steady-decline, but then falling prices, arising out of the downturn itself, coupled with good harvests in the early 1930s led to a sharp decline in farm prices and farm incomes. ${ }^{22}$ Gross farm income in current dollars fell from $\$ 17.9$ billion in 1919 to $\$ 13.9$ billion in 1929 to $\$ 6.4$ billion in 1932 before recovering to $\$ 11.4$ billion in 1937. Net farm income after expenses fell from a peak of $\$ 9.6$ billion in 1919 to $\$ 6.3$ billion in 1929 to

\footnotetext{
${ }^{18}$ Even the United States had one costly costly, the S \& L crisis of the 1980s, and would have had more had the government not engineered (through the IMF) bailouts, e.g. as a result of the Latin American debt crisis.

19 Employing the definitions of Reinhart and Rogoff (2009), the proportion of countries experiencing new external debt crises reached as high as 40 percent in the mid-1980s, and the proportion of countries experiencing banking crises reached 30 percent in the late 1990s. These were the highest since the Second World War and represented a precipitous increase since the moderate period between 1945 and 1980 (Reinhart and Rogoff, 2009, p. 74).

20 There have been extensive recapitalizations, both through the issue of new shares and (sometimes forced) retention of high earnings (facilitated by the low interest rates at which the banks can get access to funds). Still, critics argue that what has been done is not enough, that banks continue with highly risky activities, that their lack of transparency makes it difficult to judge the adequacy of their capital, and that, as a result, weaknesses in the financial sector continue to plague the economy. The lack of confidence in the financial sector is manifested by the high volatility of bank share prices. Still, the most direct consequence of the weaknesses in the financial sector should be on the level of investment, and, apart possibly for the availability of finance to SME's, this does not seem to be impaired by weaknesses in the financial sector.

${ }^{21}$ Far more important than relative resource endowments is knowledge, so that what matters is dynamic comparative advantage, which is endogenous, and which can change markedly over time (Greenwald and Stiglitz, 2006, 2012).

22 Prices in general began to decline, although wages held steady in 1930; but then a deflationary spiral started in 1931. Conditions were worse in farming areas, where commodity prices plunged, and in mining and logging areas, where unemployment was high and there were few other jobs (Hamilton, 1987; Blum et al., 1970). To counteract these tendencies, the National Recovery Administration set minimum prices and raised wages, to increase the purchasing power, and cut farm production to raise prices (Rensberger, 1996). As detailed by Chandler (1970, p. 58), "In contrast to behavior in most other industries, real output in agriculture did not fall [...] total farm output in 1931 and 1932 was slightly higher than in 1929. The most important reasons [...] were the recognition by each individual farmer that he could not raise prices by reducing his output [... ]" Chandler concludes (1970, p. 59), "Thus, the entire decrease in the money incomes of farmers resulted from declines in the prices of farm products [...] by 1932, prices received by farmers had fallen 56 percent below their levels in 1929, while prices paid by farmers had declined only 32 percent."
} 
$\$ 1.9$ billion in 1932 . It recovered to $\$ 5.7$ billion in 1937 and fell to $\$ 4.2$ billion in 1938 where it remained through $1940 .^{23}$ Farmers and the related service workers who supported them (amounting to about 35 percent of US population) had almost all their capital invested in rural houses, farm equipment, land, local structures and related equipment. The sharp decline in the value of this capital coupled with the simultaneous decline in farm income impaired the financial positions of farmers and their local lending institutions. Thus, farmers could not afford to migrate to the cities and the benefit of higher farm productivity to the world as a whole was lost. In the US, farm population, which declined from 29.9 to 24.8 percent of the overall population from 1920 to 1929 , fell by just 1.4 percentage points to 23.4 by $1940 .^{24}$

The fall in agricultural prices can be thought of as purely redistributive: farmers lose, those in the urban sector gain. ${ }^{25}$ The resulting decline in rural demand for industrial output would have outweighed any increase in urban demand as long as the marginal propensity to increase consumption by urban households was lower than the marginal propensity to reduce consumption by rural households. Several factors made such an outcome likely. First, budget constrained rural households would have been forced to reduce their consumption of industrial goods sharply and immediately. Newly better-off industrial households would have had the freedom to adjust more slowly to their higher real incomes. Second, if the marginal propensity to consume declines with income, the per dollar impact of declining incomes among already relatively poor rural households would have been larger than the impact of rising incomes for richer urban households. Third, the failure of rural financial institutions and the impairment of rural assets would have greatly limited the ability of borrowing to offset the effects on demand of declining rural incomes. The stimulative impact of lower lending constraints on largely unconstrained urban households would have been far smaller. The net effect of the collapse of agriculture would, therefore, have been a parallel decline in overall urban industrial demand. ${ }^{26}$

In this context, the role of World War II in ending the Great Depression is especially notable. On the one hand, the rise in output during the War was driven by a standard Keynesian stimulus. However, this raised the question, which loomed especially large in Keynes' mind, of what would happen when the War and the associated spending ended. In fact, there was no return to the Depression, which was a considerable surprise to contemporary economists, especially Keynesians. However, in the context of the structural model outlined above, the War represented an almost ideal industrial policy. First, it led to the relocation and retraining of a large fraction of the rural labor force either in War industries or through the military forces themselves. ${ }^{27}$ By doing so it greatly reduced the post-War cost of rural-urban migration. The transition from industrial production for the military to industrial production for consumers was a far easier transition that the transition from rural/agriculture to urban/industrial. Moreover, through the GI bill and other post-War programs the government absorbed the cost of retraining large fractions of the labor force, ensuring that they had the skills required for the new economy that was then emerging. Moreover, government housing programs helped absorb some of the costs of the rural-tourban migration. Second, forced savings during the War provided the purchasing power necessary to solve the coordination problem by creating the temporary demand necessary to finance initial employment in industrial jobs in the immediate aftermath of the War. Significantly, strong agricultural countries, like Argentina, which did not participate in the War, appear never to have recovered their prior prosperity in its wake. Their workers were stuck in the rural labor force, unable to make the smooth transition to a manufacturing economy-even though they had managed the Great Depression "better" as a result of exchange rate adjustments that did a better job of maintaining rural incomes.

\section{Reinterpreting the current crisis}

Today, the sector in terminal decline appears to be manufacturing. As was the case for agriculture in the Depression era, productivity growth has been rapid and in emerging economies like China and India, extensive new manufacturing "lands" have been brought into cultivation. At the same time, growth in global demand for manufactures has lagged as incremental income has increasingly been spent on medical care, education and financial and other services. The result has been a longterm decline in manufacturing employment and prices, and in countries like the US and the UK, the migration of most of the labor force out of manufacturing. Consistent with our hypothesis, Autor and Dorn (2011) report "dwindling manufacturing

\footnotetext{
23 Source: Historical Statistics of the United States Colonial Times to 1970, pp. 483-4. With GDP in 1938 of $\$ 84.7$, the $\$ 11.7$ billion decline in farm income (say compared to 1920) represented a loss of 13 percent of GDP. Nominal GDP was: $\$ 84$ billion in 1919, \$103.1 billion in 1929 , \$58 billion in 1932 , and $\$ 84.7$ billion in 1937; while at 1958 prices it was $146.4,203.6,144.2$ and 203.2 , respectively.

24 Source: Historical Statistics of the United States Colonial Times to 1970.

25 In an open economy, there is a net loss (if the country is a food exporter, like Argentina or the US) or a net gain (if the country is a net food importer).

26 In the formal model presented later, there is one further effect: the decline in prices leads to a substitution away from manufactured goods. This strengthens the adverse impacts on the urban sector. While the positive effect of the substitution effect partially offsets the direct negative effect of the productivity shock on rural incomes, so long as the system is stable, it can only partially do so (for empirical data on the subject, see Bell, 1940 ; Swanson and Williamson, 1972).

Note too that increased uncertainty of future income, as the crisis evolved, may have reinforced these effects, as even urban workers who retained their jobs and benefited from lower agricultural prices faced a risk of a job loss, with poor prospects of reemployment. The model below does not incorporate this effect, or one other, that may be playing a role in the current crisis: the resulting weaknesses in the urban labor market may lead to some lowering of real urban wages (even in the presence of efficiency wage concerns), and the resulting intra-sectoral redistribution may have an adverse effect on aggregate demand.

27 Recall, there was a net outmigration between 1942 and 1944 of around $6.4 \mathrm{~m}$ people from the farm population compared to a net inmigration of around 700,000 over the 1931-1934 period. Carter et al. (2006).
} 
employment and rising unemployment" (p. 9) and that "real wage growth in service occupations substantially outpaced that in other low skill occupations, averaging six percent per decade between 1980 and 2005" (p.3). The decrease in employment in manufacturing from its peak in 1979 of 19.6 million has been (as of January 2012) about 7.7 million, i.e. a 39 percent decline. Moreover, 5.5 million manufacturing jobs have been lost since July 2000 alone, accounting for some 71 percent of the total decline since 1979.28 During the same period (179-2011) the number of people employed in the service sector has increased by 76 percent. $^{29}$

It makes sense that growth in services has not solved the crisis of unemployment in manufacturing: there cannot be seamless movement between sectors. Moving workers from agricultural to manufacturing entailed not only geographical movement, but retraining. The soft skills required for effectiveness in manufacturing (the ability to show up on time every day, to engage in often repetitive tasks over long periods of time, etc.) are markedly different from those that are learned on the farm, and of course the higher paid urban jobs require quite specific skills, that can often be obtained only through extended and expensive training. Service sector jobs are sometimes available in the same locale, but as the manufacturing sector declines, those parts of the country that rely heavily on manufacturing see a concomitant reduction in service sector jobs. But again, even apart from this mobility cost, there is a cost to retraining, particularly if skilled manufactured workers are to obtain employment in the service sector at wages approaching those in their previous employment.

However, countries like Japan, Germany, China, Korea, Indonesia, Thailand, Malaysia and many other emerging economies remain committed to supporting outsized manufacturing sectors either as protection for politically powerful firms and unions or as a source of export driven growth or simply because of a misplaced belief in "making things" as the only basis for a healthy economy. ${ }^{30}$ While the focus of analysis in this paper is mainly the United States, the trend of a loss of jobs in manufacturing is not at all limited to North America. Chinese manufacturing employment is similarly in decline. A widely reported study by Alliance Capital Management has reported that, for example, China lost $16 \mathrm{~m}$ manufacturing jobs between 1995 and 2002. ${ }^{31}$ Incomes in China and other rapidly expanding manufacturing economy can, in fact, increase rapidly even as incomes in the United States for several reasons: (a) even if prices in manufacturing (relative to some numeraire) are declining, the increase in their labor productivity is so great that incomes can increase; (b) incomes in manufacturing are considerably in excess of those in agriculture, so the expansion of manufacturing in their economy contributes to income growth (just as the fact that manufacturing wages of say, high school graduates, is higher than that of those in the service sector with comparable education means that the shift of these workers from manufacturing to services lowers national income.) Moreover, going beyond the model presented here, there may be large cross-sector externalities (including learning externalities) associated with the expansion of the manufacturing sectors (see Greenwald and Stiglitz, 2006).

In the face of underlying adverse trends, these countries cannot sustain their manufacturing sectors with domestic demand alone.

As a result, in the current crisis-as in the Great Depression-there has been intense export competition driven primarily by exchange rate management. ${ }^{32}$ In the aggregate, since the sum of all international deficits and surpluses must be zero, these efforts can succeed only in transmitting the deflationary impact of manufacturing decline to other countries, especially reserve currency countries like the US with relatively little control over their exchange rates. ${ }^{33}$ It cannot eliminate the problem. This will occur only with the full migration of global resources out of manufacturing to services. Until the structural imbalance is eliminated, global demand growth is likely to continue to be disappointing. However, continued Keynesian stimulus will mitigate the problem during an extended transition.

\section{A simple model}

A simple two sector model with an urban sector producing manufactured goods and a rural sector producing food captures some of the essential insights. For simplicity, we assume

\footnotetext{
${ }^{28}$ Analysis of Bureau of Labor Statistics data presented by the St. Louis Fed, available online at http://research.stlouisfed.org/fred2/data/MANEMP.txt (accessed February 21, 2012).

29 Analysis of Bureau of Labor Statistics data on the service-providing industries supersector, available at http://www.bls.gov/iag/tgs/iag07.htm\#workforce (accessed February 21, 2012). If only private, service-providing, seasonally adjusted jobs are counted, the increase has been from 48 million in 1979 to 92 million in 2012-a 92 percent increase.

30 There are good reasons for countries to have industrial policies, focusing on the externalities associated with learning and research, the benefits of which can extend beyond the firm to others in the sector, or even beyond the sector (see Greenwald and Stiglitz, 2006). But the policies to which we refer are directed at protecting old industries, in which the country has lost its comparative advantage, and not likely to regain it.

${ }^{31}$ As discussed by Baum, C. “So Who's Stealing China's Manufacturing Jobs?”, Bloomberg available at http://www.bloomberg.com/apps/news?pid= newsarchive \&sid=aRI4bAft7Xw4.

That same study reports that, due to automation, this is a global trend, with manufacturing jobs being shed worldwide.

32 In the Great Depression, countries tried to stoke the demand for manufacturing by beggar-thy-neighborpolicies of trade restrictions. What is distinctive about this crisis is that such trade restrictions have been remarkably limited.

33 Debt problems have generated a new form of beggar-thy-neighbor policies. In order to generate resources to pay back what is owed, countries are forced to cut back spending, with obvious spill-overs to others. Beggar-thy-neighbor policies through exchange rate management have thus been complemented by beggar-thy-self policies. For other countries, though, the effects are not dissimilar (see Stiglitz, 1999).
} 
- fixed wages in the urban sector (motivated, for instance, by efficiency wage considerations) but flexible wages in the rural sector;

- constant returns to scale in agriculture (it is easy to generalize the results), but diminishing returns in manufacturing.

The two basic equations are that the demand for agricultural goods equal the supply and the demand for manufactured goods has to equal the supply. Demand is actual demand, which depends on the actual employment level:

$$
\begin{aligned}
& \beta \alpha=\beta D^{A A}(p, p \alpha)+E D^{M A}\left(p, w^{*}\right) \\
& H(E)=\beta D^{A M}(p, p \alpha)+E D^{M M}\left(p, w^{*}\right)+I
\end{aligned}
$$

where $\beta$ is the labor force in agriculture, $(1-\beta)$ is the labor force in industry, $\alpha$ is productivity in agriculture, $D^{i j}$ is demand from those in sector $i$ for goods from sector $j, w^{*}$ is the (fixed) efficiency wage in the urban sector, $I$ is the level of investment (assumed to be industrial goods), $p$ is the price of agricultural goods in terms of manufactured goods, which is chosen as the numeraire, and $E$ is the level of employment $(E \leq 1-\beta)$; and where we have normalized the labor force at unity.

The labor force in each sector is initially assumed fixed. The first argument in the demand function is the price, the second is income. $H(E)$ is the production function for industrial goods. ${ }^{34}$

Eq. (1) defines an upward sloping curve between employment $E$ and price (curve $A A$ ): when employment in the urban sector is higher, prices of agriculture rise. However, since urban individuals spend a relatively small fraction of their income on food, the slope is relatively flat.

Eq. (2) can be thought of as defining the relationship between prices in the agricultural sector and employment in the urban sector (curve $M M$ ): when prices of agricultural goods are high, demand for industrial goods benefit from both an income effect (increased income in the rural sector) and a substitution effect, and hence employment increases.

The intersection of the two curves is the equilibrium. Because the two curves are both upward sloping, there can in principle be multiple equilibria. In one, high urban employment leads to high agricultural prices and incomes, which supports high industrial employment; in the other, a low level of urban employment leads to low agricultural prices, and the low farm incomes lead to low demand for industrial goods. In this paper, we do not explore this possibility. We focus on the case where the slope of the $A A$ curve (giving $p$ as a function of $E$ ) is flatter than the slope of the $M M$ curve. This assumption is motivated in part by the stability analysis of Appendix A, where we show that, under natural assumptions of dynamics, this is necessary if the system is to be stable. ${ }^{35}$

In the remainder of the paper, we assume that the stability condition:

\section{A.1. (stability condition)}

$1 / Z_{p}^{M}>Z_{E}^{A}$ where $1 / Z_{p}^{M}$ is the slope of the $M M$ curve (defined as $E$ as a function of $p$ ) and $Z_{E}^{A}$ is the slope of the $A A$ curve (defined as $p$ as a function of $E$; with both functions defined in Appendix A.1. The previous footnote provides sufficient conditions for this condition to be satisfied in terms of the underlying demand and supply functions).

\section{Comparative statics}

In this section, we ask what happens to the equilibrium in the face of four kinds of shocks:

\footnotetext{
${ }^{34}$ For simplicity, we assume that none of profits are consumed, and investment is fixed.

${ }^{35}$ Define $D^{A}(p ; E)-\beta D^{A A}(p, p \alpha)+E D^{M A}\left(p, w^{*}\right)$ as total demand in the agricultural sector, and define $D^{M}(p, E)$ similarly. Then the slope (elasticity) of the $A A$ curve is given by $-E D^{M A} / p D^{A \prime}=\left(1-s^{A}\right) / \varepsilon^{A}$ where $\varepsilon^{A}$ is the price elasticity of total demand in the agriculture sector and $s^{A}$ is the share of consumption of agricultural goods by those in the agricultural sector.

The slope (elasticity) of the $M M$ curve is $-\left[H^{\prime} E-E D^{M M}\right] / p D^{M \prime}-\eta^{s}-\sigma^{M} / \varepsilon^{M}$, where $\eta^{s}$ is the elasticity of output with respect to employment in manufacturing, $\sigma^{M}$ is the share of manufactured goods consumed by those in the urban sector, and $\varepsilon^{M}$ is the elasticity of demand of manufactured goods with respect to the agricultural price. When the price of agricultural goods increases, there are two effects: a substitution effect away from food and toward manufactured goods, and an increase in incomes of those in the rural sector and a decrease of those in the urban sector. In a representative agent model, the redistribution effects cancel and there is only the substitution effect. If the elasticity of substitution is low, $\varepsilon^{M}$ will be small. On the other hand, an increase in agricultural prices results in a substitution effect against agriculture (again related to the elasticity of substitution) combined with an income effect (farmers are better off, workers worse off).

Hence, we assume
}

$$
\left(\eta^{S}-\sigma^{M}\right) / \varepsilon^{M}>\left(1-s^{A}\right) / \varepsilon^{A}
$$

If price elasticities (appropriately defined) are approximately the same, then stability ( $A A$ being flatter than $M M$ ) simply requires that

$$
\left(\eta^{s}-\sigma^{M}\right)>\left(1-s^{A}\right)
$$

If $\eta^{s} \approx 1$, this will be true if $s^{A}>\sigma^{M}$, i.e. agriculture workers consume a larger fraction of their own goods than urban workers of their good. 


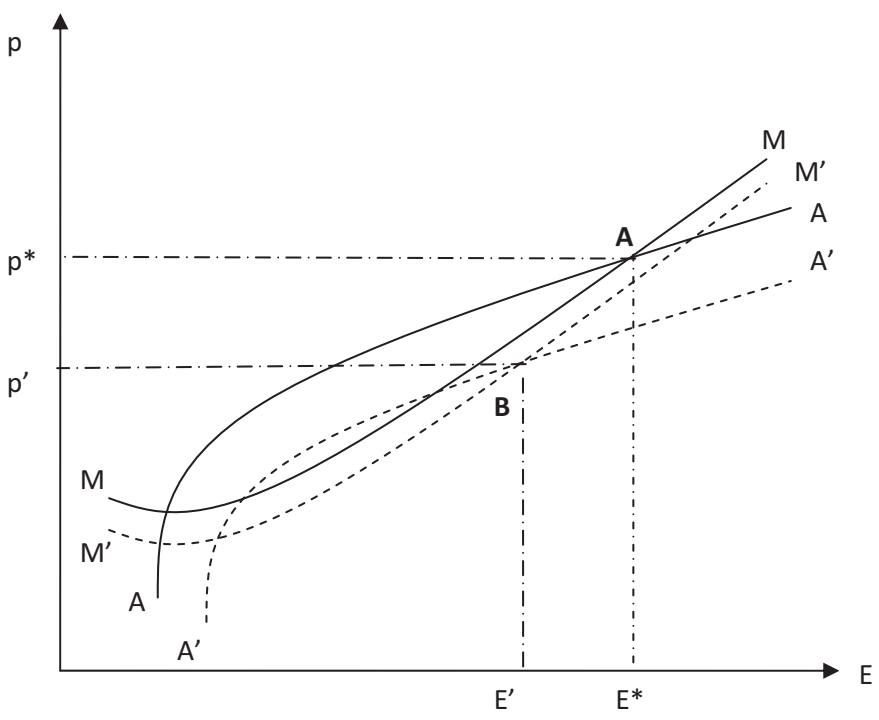

Fig. 1. The effects of an increase in agricultural productivity.

- agricultural productivity;

- Keynesian stimulus;

- wage adjustment; and

- migration.

\subsection{The effects of an increase in agricultural productivity}

The first is an increase in agricultural productivity, such as occurred in the 1920s. We show that under plausible conditions, this leads to an increase in urban unemployment.

At any fixed level of $E$, an increase in productivity $\alpha$ shifts the supply curve out, leading to a decrease in prices. The effect is mitigated by the increase in farmers' income (at any level of prices), but so long as $1>p D_{y}^{A A}$, which will be the case if the income elasticity of the demand for food by rural workers is small enough, then the indirect income effect is outweighed by the supply side effect, and the curve $A A$ shifts down. As Fig. 1 illustrates, in the new equilibrium, agricultural prices and urban employment are markedly lower.

At the same time, at each price, income of agricultural workers increases, and so demand for manufactured goods increases. Thus MM shifts to the right, undoing some of the direct effects noted above. But normally equilibrium employment and prices will be lower than in the original equilibrium.

Proof. See Appendix A.2.

The first condition ensures that the $A A$ curve is flatter than the $M M$ curve, and follows naturally from reasonable hypotheses concerning stability. The second ensures that an increase in $\alpha$ shifts the $A A$ curve down, and requires only that there is an increase in net supply from the agricultural sector as a result of an increase in productivity, so that the market clearing price is lower. The third condition ensures that the downward shift in the $A A$ curve is greater than that of the $M M$ curve, so that equilibrium requires a reduction in $E$ (given the stability condition (a)). ${ }^{36}$

Under not implausible restrictions on the relevant parameters of the demand functions, all three of the conditions can easily be satisfied.

\subsection{Impact of Keynesian stimulus}

Assume now that we introduce government spending, replacing Eq. (2) with

$$
H(E)=\beta D^{A M}(p, p \alpha)+E D^{M M}\left(p, w^{*}\right)+I+G
$$

It immediately follows that even though the origins of the crisis was structural, Keynesian stimulus (an increase in $G$ ) increases both employment and rural prices. As $G$ increases, $M M$ shifts to the right, as in Fig. 2.

\footnotetext{
${ }^{36}$ Letting (without loss of generality) the initial value of $\alpha=1, p=1$.

$\left(D_{\alpha}^{A}-\beta\right) / D_{p}^{A}=1-s^{A} \eta_{I}^{A A} / \varepsilon^{A}$, where $\eta_{I}^{A A}$ is the agricultural goods income elasticity in the agricultural sector. $D_{\alpha}^{M} / Z_{p}^{M}=\left(1-\sigma^{M}\right) \eta_{I}^{A M} / \varepsilon^{M}$, where $\eta_{I}^{A M}$ is the income elasticity of the agricultural sector for manufactured goods. It is clear that this condition can easily be satisfied.
} 


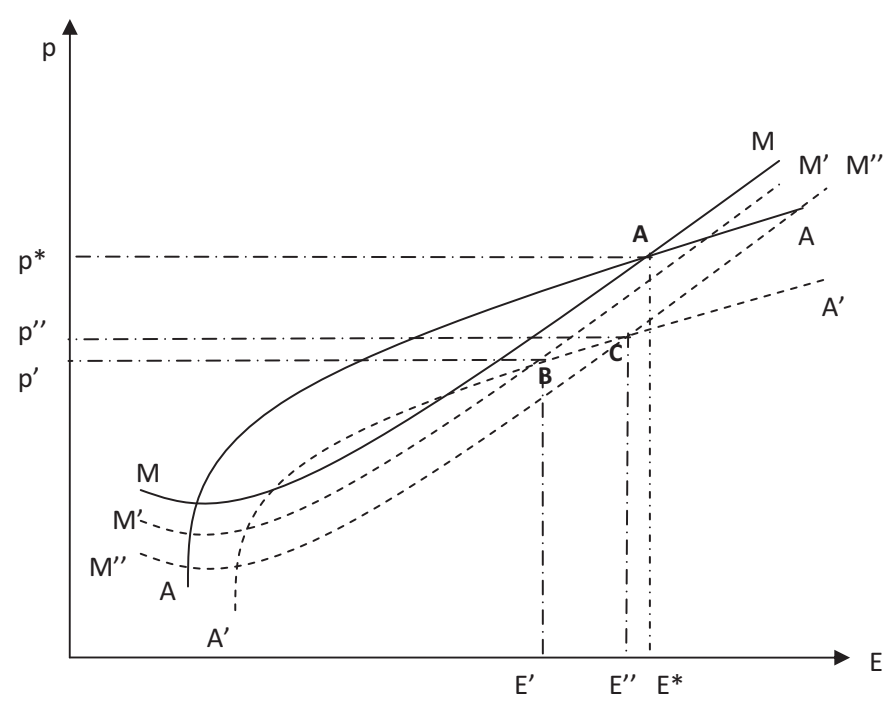

Fig. 2. Impact of Keynesian stimulus: an increase of $G$ (curve $\left.M M^{\prime \prime}\right)$ increases both employment and rural prices.

Theorem 2. Under the stability condition A.1., as increase in government expenditure increases urban employment and raises agricultural prices and incomes. ${ }^{37}$

\subsection{The effects of wage adjustments}

We have assumed that urban wages are fixed, e.g. as a result of efficiency wages. Different efficiency wage theories provide different predictions for what might happen to real wages denominated in manufactured goods when food prices fall. Some versions (change as labor turnover theories) are consistent with no changes. Others, such as the Shapiro-Stiglitz incentives-based model, predict a decline in real wages, denominated in manufactured goods. This shifts down the $A A$ curve (demand for food decreases with the decrease in urban workers' incomes), which lowers employment and prices further. Such decreases did, of course, occur in the Great Depression. But now, the second round effect in the urban sector reinforces this effect. At any level of employment, for demand for urban goods to equal supply, the price of urban goods has to fall, i.e. the price of rural goods has to rise, i.e. the $M M$ curve shifts up, so that in equilibrium, urban employment is lowered even more (and agricultural goods prices are lowered more) (see Fig. 3).

Theorem 3. Under the stability condition A.1., as decrease in urban real product wages increases urban unemployment and lowers agricultural prices and incomes. ${ }^{38}$

\subsection{The effects of migration}

The decrease in rural income $(d p \alpha / d \alpha<0)$ would normally have induced migration to the urban sector, if migration were costless, and if there were job opportunities in the urban sector. But with urban employment down and the value of rural assets down, migration is inhibited. Assume a migration function of the form

$$
\frac{d \beta}{d t}=F\left(w^{*}-p \alpha, p \alpha, W, V\right)
$$

where $W$ is rural wealth and $V$ is urban job vacancies. Migration is affected by wage differentials, the ability of rural workers to afford migration, related both to their wages and wealth, and the number of vacancies in the urban sector. We assume that

$$
F\left(w^{*}-p \alpha, p^{*} \alpha W, 0\right)=0
$$

if there are no vacancies, there will be no migration.

In steady state,

$$
V=\mu E^{*}
$$

\footnotetext{
37 By hypothesis, we assume that Ricardian equivalence does not hold, so that the future tax liabilities do not lead to an equal and offsetting reduction in consumption today. This follows naturally from our assumptions of capital market imperfections, which underlies the entire analysis.

38 Similar assumptions apply as stated in footnote 37.
} 


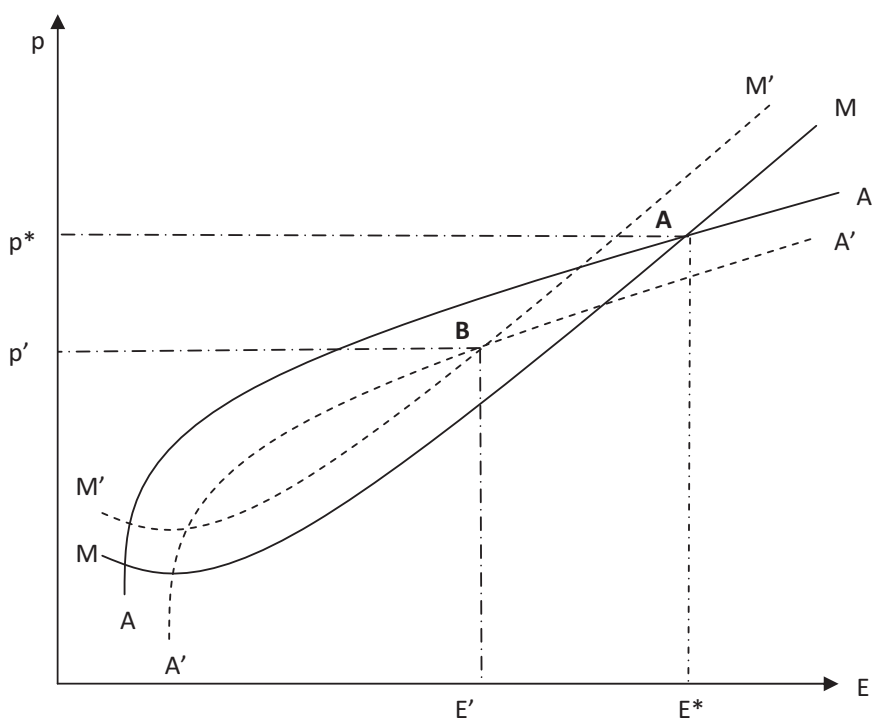

Fig. 3. The effects of wage adjustments.

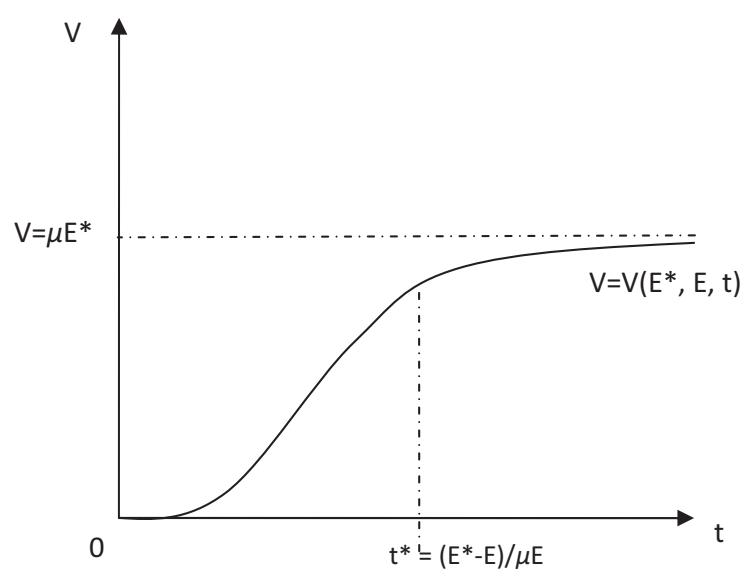

Fig. 4. The vacancy curve.

where $\mu$ is the death rate. But if an economy experiences a shock, so equilibrium moves from $E^{*}$ to a lower level of employment $E$, vacancies are obviously much smaller:

$$
V=V\left(E^{*}, E, t\right)
$$

where $t$ is the length of time since the shock. The vacancy curve is illustrated in Fig. 4. Initially, there will be (virtually) no vacancies, as workers that have been laid off are rehired at the death of existing workers. A simple (and extreme) version of this process has

$$
\begin{aligned}
V & =0 \text { for } t<t^{*} \\
& =\mu E \text { for } t \geq t^{*}
\end{aligned}
$$

where $t^{*}=\left(E^{*}-E\right) / \mu E$.

In short, if the labor market were in equilibrium before the productivity shock, then even though rural wages have fallen markedly below urban wages, there is no migration after the shock, because there are no vacancies. The equilibrium persists for a period $t^{*}$, until all those laid off have been recalled to work. Even then, migration will be limited because of the adverse shock to their ability to pay for migration $(W$ and $p \alpha)$.

Assume now, however, the government provides a Keynesian stimulus, which, as we have noted, increases $E$ and $p$. This reduces the time before which vacancies appear, and increases the resources available to those in the rural sector to migrate. On both accounts, it facilitates the process of structural adjustment. 


\section{Concluding remarks}

In this paper we have proposed a structural interpretation of the Great Depression of the $30 \mathrm{~s}$ and of the ongoing Great Recession. Our interpretation is unorthodox, but supported by a narrative and empirical evidence. Uneven technical progress may have immiserizing consequences for the workers of the sector in which technical change occurs, if there are barriers to labor mobility. The declines in agricultural incomes in the Great Depression were major, and the New Deal made only a small dent in offsetting these. ${ }^{39}$ Wages of employed workers "trapped" in this sector fall and the reduction of sectoral purchasing power reverberates to the macroeconomy. There is therefore a propagation of technical change which can cause a long lasting slump because of slow sectoral adjustment.

In order to illustrate this interpretation, we proposed a simple two sector model of the macroeconomy in which technical progress occurs in one sector and spills over perversely to other sector.

Our analysis argues that market processes themselves may not lead to "good" outcomes. Information is imperfect and costly to obtain. The result is that capital and labor markets work markedly different from the way that they are assumed to work in neoclassical models. Credit and labor markets may not clear. Even though rural workers could increase their income if they could costlessly move to the urban sector, the move is not costless, and they may not be able to obtain the requisite capital. Note that there are three distinct "market failures" (we hesitate to call them that, because it is not a failure that information is costly or that labor mobility is costly, any more than it is a failure that to obtain outputs, one must put in inputs): (a) mobility is costly; (b) individuals may not be able to obtain funds; and (c) there are (real) wage rigidities in the urban sector.

The central result of this paper is to establish that there are plausible conditions under which technological change in the rural sector can be immiserizing-leading to lower incomes in both the rural and urban sectors.

Conservatives like to blame workers for their own travails. If only wages were lower, then the problem of unemployment would be resolved. In efficiency wage models, it is not unions or government legislation that causes high wages, but the market itself. Breaking unions or eliminating minimum wage legislation will not resolve the problem, and restore full employment. But we showed that, if somehow one could lower wages slightly, that change is likely to increase unemployment.

The paper showed moreover that in such a situation, even though the "crisis" is caused by a structural change (improved agricultural productivity), fiscal policy could be welfare improving in the short run, increasing incomes and employment in both sectors.

This paper opens up a new research program for understanding the causes of economic deep downturns and how to respond to them. We note here a few extensions of our analysis.

For instance, here, the characterization of technical change so far is very simple. It is a permanent jump in labor augmenting technical progress. In a more dynamic model, we could analyze changes in the stochastic process governing technological change. Anticipations of technological change by markets might pre-emptively impose the losses that we have identified as making mobility difficult; at the same time, increases in uncertainty about future technological progress might lead to lower levels of aggregate demand.

In our analysis, we held investment as fixed. But as aggregate demand falls and urban employment and output declines, it is natural that investment declines: the consequence of this is to exacerbate the decline in urban employment and rural incomes. A fully articulated model would, of course, make investment endogenous.

Moreover, barriers to labor mobility are so high as to prevent movement across sectors completely. We have discussed, with a particular model of migration, how fiscal policy can accelerate the transition process. Other policies, more directed at facilitating migration (and dependent on the kinds of investment required for a successful movement of workers), may be equally or more effective in accelerating the transition (and thereby reducing the deadweight loss associated with "trapped" labor).

There is a growing consensus that the recovery from the current crisis will take a long time, with many forecasts suggesting that it will take more than a decade for full employment to be restored. What is required is more than just the restoration of balance sheets. This paper argues that a structural shock was a major part of the cause of the Great Depression, and the economy only recovered when public policies led to a structural response. The implications for the current crisis should be clear.

\section{Appendix A.}

\section{A.1. Continuous time}

We start with a continuous time definition of the dynamic system:

$$
\dot{p}=D^{A}(p, \alpha, E)-\beta \alpha
$$

\footnotetext{
39 Moreover, as Cary Brown (1956) points out, the increased federal expenditures were not sustained, and largely (or more than) offset by reductions at the state and local level.
} 


$$
\dot{E}=D^{M}(p, \alpha, E)-H(E)
$$

where a dot on a variable denotes the time derivative: $\dot{x} \equiv d x / d t$

$$
\begin{aligned}
& D^{A}(p, \alpha, E):=\beta D^{A A}(p, p \alpha)+E D^{M A}\left(p, w^{*}\right) \\
& D^{M}(p, \alpha, E):=\beta D^{A M}(p, p \alpha)+E D^{M M}\left(p, w^{*}\right)+I
\end{aligned}
$$

Eq. (A.1) says that prices in the agricultural sector increase when demand exceeds supply, while Eq. (A.2) says that employment in the urban sector increases when demand exceeds supply. Denoting the partial derivative of a function as $y_{x} \equiv \partial y / \partial x$ we can write: $D_{p}^{A}=\beta\left(D_{p}^{A A}+\alpha D_{y}^{A A}\right)+E D_{p}^{M A}$ where $D_{y}^{A A}=\partial D^{A A} / \partial y$ i.e. the derivative of $D^{A A}$ wrt per capita income of a rural worker, $y=p \alpha$. Notice that $D_{y}^{A A}>0, \quad D_{p}^{A A}<0 ; \quad D_{p}^{M A}<0$.

Moreover, we assume $\beta \alpha D_{y}^{A A}<-\left(\beta D_{p}^{A A}+E D_{p}^{M A}\right)$, i.e. an increase in agricultural prices engenders a net surplus, that is the reduction in demand at fixed income from an increase in price is smaller than the increase in demand from the income effect on rural farmers. Therefore

$$
\begin{aligned}
& D_{p}^{A}<0 \\
& D_{E}^{A}=D^{M A}\left(p, w^{*}\right)>0 \\
& D_{p}^{M}=\beta\left(D_{p}^{A M}+\alpha D_{y}^{A M}\right)+E D_{p}^{M M}
\end{aligned}
$$

From $D_{p}^{A M}>0, \quad D_{p}^{M M}>0, \quad D_{y}^{A M}>0$ follows that $D_{p}^{M}>0$

$$
D_{E}^{M}=D^{M M}\left(p, w^{*}\right)>0
$$

The demarcation curves can be computed as follows.

From $\dot{p}=0$, i.e. $D^{\mathrm{A}}(p, \alpha, E)-\beta \alpha=0$ we can derive the $A A$ curve, whose generic equation (ignoring shift parameters) is

$$
p=Z^{A}(E)
$$

The slope of the $A A$ curve is $Z_{E}^{A}$ which can be computed using the implicit differentiation theorem:

$$
Z_{E}^{A}=-\frac{D_{E}^{A}}{D_{p}^{A}}>0
$$

Notice that the elasticity of the equilibrium price with respect to employment along the $A A$ curve is

$$
Z_{E}^{A} \frac{E}{p}=-\frac{D_{E}^{A}}{D_{p}^{A}} \frac{E}{p}=\frac{1-s^{A}}{\varepsilon^{A}}>0
$$

as shown earlier, where $\varepsilon^{A}:=D_{p}^{A} \frac{p}{D^{A}} ; \quad 1-s^{A}=D_{E}^{A} \frac{E}{D^{A}}=D^{M A} \frac{E}{D^{A}}$. From $\dot{E}=0$, i.e. $D^{M}(p, \alpha, E)-H(E)=0$, we can derive the $M M$ curve, whose generic equation is

$$
E=Z^{M}(p)
$$

The slope of the $M M$ curve is $Z_{p}^{M}$ which can be computed using the implicit differentiation theorem:

$$
Z_{p}^{M}=\frac{D_{p}^{M}}{H_{E}-D_{E}^{M}}
$$

The slope is positive as we assume $H_{E}>D_{E}^{M}$. Notice that we draw the $A A$ and $M M$ curves on the $(E, p)$ plane. Since $p$ is measured on the $y$-axis, the slope of the MM curve on this plane is

$$
\frac{1}{Z_{p}^{M}}=\frac{H_{E}-D_{E}^{M}}{D_{p}^{M}}>0
$$

if, as we assume, the urban sector generates a surplus from greater employment, with the incremental output exceeding the incremental demand arising from the increased employment.

Notice that the elasticity of the equilibrium price with respect to employment along the $M M$ curve is

$$
\frac{1}{Z_{p}^{M}} \frac{E}{p}=\frac{H_{E}-D_{E}^{M}}{D_{p}^{M}} \frac{E}{p}=\frac{\eta^{s} H-D^{M M} E}{\varepsilon^{M} D^{M}}=\left(\eta^{s}-\sigma^{M}\right) \frac{1}{\varepsilon^{M}}>0
$$

as shown earlier, where $\varepsilon^{M}:=D_{p}^{M} \frac{p}{D^{M}} ; \quad \eta^{s}:=H_{E} \frac{E}{H} ; \quad \sigma^{M}:=D^{M M} \frac{E}{D^{M}}$. Since both demarcation curves are upward sloping, there can be multiple equilibria. The steady states are determined at the intersection of the $A A$ and $M M$ curves. We will denote the (generic) steady state with $E^{*}$ and $p^{*}$. 
In order to assess the properties of (each) steady state we must compute the (associated) $2 \times 2$ Jacobian matrix. Each entry of the Jacobian matrix is the derivative of equations (A.1) and (A.2) with respect to the endogenous variables ( $p$ and $E)$, taken in the specified steady state.

Proposition 1. In continuous time, for a system of two differential equations linearized around the steady state, stability requires both eigenvalues to be negative, while saddle point instability occurs if one eigenvalue is positive and the other is negative.

The Jacobian matrix is:

$$
J=\left(\begin{array}{cc}
D_{p}^{A}<0 & D_{E}^{A}>0 \\
D_{p}^{M}>0 & D_{E}^{M}-H_{E}<0
\end{array}\right)
$$

The trace $T r=D_{p}^{A}+D_{E}^{M}-H_{E}$ is always negative.

The determinant

$$
\text { Det }=D_{p}^{A}\left(D_{E}^{M}-H_{E}\right)-D_{E}^{A} D_{p}^{M}
$$

is positive if

$$
-D_{p}^{A}\left(H_{E}-D_{E}^{M}\right)>D_{E}^{A} D_{p}^{M}
$$

i.e.

$$
\text { slope } \quad M M:=\frac{1}{Z_{p}^{M}}=\frac{H_{E}-D_{E}^{M}}{D_{p}^{M}}>-\frac{D_{E}^{A}}{D_{p}^{A}}=Z_{E}^{A}=\text { slope } A A
$$

Hence

$$
1>Z_{E}^{A} Z_{p}^{M}
$$

In this case, thanks to the Routh-Hurwitz conditions, the steady state is stable. Infact, if the determinant is positive and the trace is negative both eigenvalues are negative.

In the opposite case, i.e. if the $A A$ curve is steeper than the $M M$ curve, the determinant of the Jacobian matrix is negative and the steady state is a saddle point. In fact, if the determinant is negative, one eigenvalue is positive and the other is negative. In the figure we report one of the two possible cases, in which the $A A$ curve is concave and the $M M$ curve is convex.

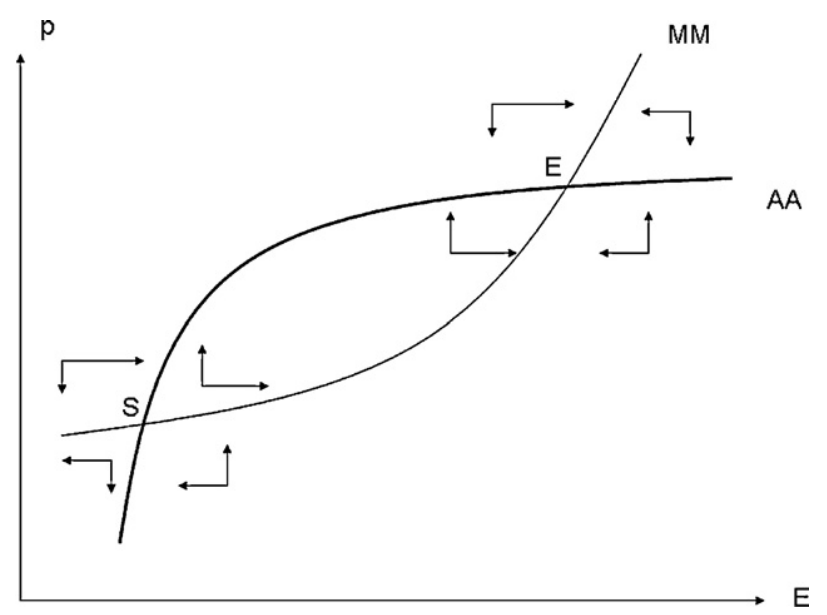

A special interesting case is where prices in the agricultural sector adjust instantaneously. Then (A.1) can be solved for $p$ as a function of $E$, as above

$$
p=Z^{A}(E)
$$

and the result substituted into (A.2) to obtain a single differential equation

$$
\frac{d E}{d t}=D^{M}\left(Z^{A}(E), \alpha, E\right)-H(E)=Z^{*}(E)
$$

with an equilibrium $Z^{*}\left(E^{*}\right)=0$ being stable if $Z^{* \prime}<0$, the condition for which can be shown to be precisely the condition derived above,

$$
1>Z_{E}^{A} Z_{p}^{M}
$$


Essentially, in this case, the economy moves along the $A A$ curve, and since above the $M M$ curve, $d E / d t>0$, if $E<E^{*}, E$ increases until it hits $E^{\prime \prime}$.

\section{A.2. The effects of an increase in agricultural productivity}

In this section, we focus on the effect of a change in agricultural productivity $\alpha$ on the relative price $p$ and employment in manufacturing $E$ when the economy is in the (stable) equilibrium. In other words, starting from

$$
\begin{aligned}
& D^{A}(p, \alpha, E)-\beta \alpha=0 \\
& D^{M}(p, \alpha, E)-H(E)=0
\end{aligned}
$$

where we compute the comparative statics derivatives $d p^{*} / d \alpha, d E^{*} / d \alpha$.

From the system above, taking the differentials we get:

$$
\begin{aligned}
& D_{p}^{A} d p+\left(D_{\alpha}^{A}-\beta\right) d \alpha+D_{E}^{A} d E=0 \\
& D_{p}^{M} d p+D_{\alpha}^{M} d \alpha+\left(D_{E}^{M}-H_{E}\right) d E=0
\end{aligned}
$$

where $D_{p}^{A}<0 ; \quad D_{E}^{A}>0 ; \quad D_{p}^{M}>0 ; \quad D_{E}^{M}-H_{E}<0$ as shown in the previous section.

Moreover it is easy to compute the following: $D_{\alpha}^{A}=\beta p D_{y}^{A A}>0, \quad D_{\alpha}^{M}=\beta p D_{y}^{A M}>0$. We assume $\beta>D_{\alpha}^{A}$ i.e. $1>p D_{y}^{A A}$, i.e. an increase in productivity (at fixed prices), generates an agricultural surplus, with the increased output exceeding the sector's own increased demand from their increased income. This will be the case if rural workers' marginal propensity to consume food is less than unity, which it surely is. From the system above, one gets:

$$
\begin{aligned}
& d p=Z_{E}^{A} d E-k_{0} d \alpha \\
& d E=Z_{p}^{M} d p+k_{1} d \alpha
\end{aligned}
$$

where $Z_{E}^{A}>0 ; Z_{p}^{M}>0$ as shown in the previous section. The parameter $k_{0}:=\left(D_{\alpha}^{A}-\beta\right) / D_{p}^{A}$ is positive since we have assumed $\beta>D_{\alpha}^{A}$. Finally $k_{1}:=D_{\alpha}^{M} /\left(H_{E}-D_{E}^{M}\right)>0$.Solving the system above for $d p, d E$ yields:

$$
\begin{aligned}
d p^{*} & =\frac{Z_{E}^{A} k_{1}-k_{0}}{1-Z_{E}^{A} Z_{p}^{M}} d \alpha \\
d E^{*} & =\frac{k_{1}-Z_{p}^{M} k_{0}}{1-Z_{E}^{A} Z_{p}^{M}} d \alpha
\end{aligned}
$$

Notice that in the stable steady state $1-Z_{E}^{A} Z_{p}^{M}>0$. Hence

$$
\begin{array}{ll}
\frac{d p^{*}}{d \alpha}<0 & \text { if } Z_{E}^{A}<\frac{k_{0}}{k_{1}} \\
\frac{d E^{*}}{d \alpha}<0 & \text { if } \frac{1}{Z_{p}^{M}}<\frac{k_{0}}{k_{1}}
\end{array}
$$

where

$$
\frac{k_{0}}{k_{1}}:=\frac{D_{\alpha}^{A}-\beta}{D_{\alpha}^{M}} \times \frac{\left(H_{E}-D_{E}^{M}\right)}{D_{p}^{A}}
$$

We know that $1 / Z_{p}^{M}>Z_{E}^{A}$ in the stable steady state. Therefore a sufficient condition for $d p^{*} / d \alpha<0, d E^{*} / d \alpha<0$ is:

$$
\frac{k_{0}}{k_{1}}>\frac{1}{Z_{p}^{M}}
$$

Using the expression previously derived for $1 / Z_{p}^{M}$, we can rewrite this condition as

$$
\frac{\left(D_{\alpha}^{A}-\beta\right)}{D_{p}^{A}}>\frac{D_{\alpha}^{M}}{D_{p}^{M}}
$$

which has a natural interpretation: the downward shift in the $A A$ curve must be greater than the downward shift in the $M M$ curve, so that at the old $E$, at the price that clears the agricultural market, there is excess demand for labor. The condition can be rewritten

$$
\frac{\left[1-s^{A} \eta_{I}^{A}\right]}{\varepsilon_{p}^{A}}>\frac{\left[1-\sigma^{M}\right]}{\varepsilon_{p}^{M}}
$$


where $\eta_{I}^{A}$ is the income elasticity of agricultural goods in the agricultural sector. Given that $\eta_{I}^{A}$ is relatively small, and natural assumptions of the relative price elasticities, this condition will easily be satisfied.

When the above condition is satisfied, an increase in agricultural productivity shifts the $A A$ curve down more (at the old $E$ ) than it does the $M M$ curve-the impact effect is greater than the second round adjustments from the urban sector.

\section{A.3. Inventories}

The above analysis, while conventional, is unsatisfactory in two respects: (a) it does not describe what happens to goods that may have been produced, but not consumed (i.e. inventories) and (b) it does not describe what happens to income which is not spent (i.e. savings). Introducing a full dynamic analysis is complicated, and beyond this short paper, though the analytics are well understood. Qualitative results are likely to look similar to those depicted above, with convergence likely to be less smooth.

Consider, for instance, the case where the agricultural market always clears, but excess production of manufacturing is put into inventories (and shortages taken out of inventories.)

Let $M=$ inventories, and let the desired level of inventories equal $\kappa H(E)$. Let IM be intended inventory accumulation (decumulation)

$$
\mathrm{IM}=\mu(\kappa H(E)-I)
$$

Firms attempt to accumulate inventories when their desired level exceeds the actual level. The actual level of inventory accumulation is given by the difference between aggregate supply and demand

$$
\frac{d I}{d t}=\Psi\left[H(E)-\varphi^{* *}(E, I)\right]
$$

where $\Psi$ represents the faction of excess production that is wasted in moving goods in or out of inventory, and where $\varphi^{* *}(E$, $I$ ) is the equilibrium level of employment corresponding to a particular level of employment and inventories (noting that total planned investment includes Io, investment in plant and equipment, plus planned inventory investment, $\operatorname{Im}$.). If $\Psi=0$, what is produced is a perishable, and there are no inventory accumulations from excess production.

At the same time, employment adjustment is now given by

$$
\left.\frac{d E}{d t}=\lambda\left[E^{*}-E\right]==\lambda\left[\varphi^{* *}(E, I)\right)-E\right]
$$

We now have a pair of differential equations in $d E / d t$ and $d I / d t$.

The equilibrium of the system is the same as before, Inventory accumulation is zero along the line $H(E)-\varphi^{* *}(E, I)$, noting that as $E$ increases, there are two effects: planned inventory accumulations increase, but so too would unplanned (if the absence of the increase in planned inventories). In the absence of unplanned inventory accumulations, inventories would be in equilibrium along the curve

$$
I=\kappa H(E)
$$

Now, however, because of unplanned inventory accumulations, for $E<E^{*}, d I / d t$ is negative along that curve. We thus postulate that $d I / d t=0$ along a curve that is steeper than $\kappa H(E)$.

In the absence of inventory accumulation, we know that $E$ is falling for $E$ greater than $E^{*}$ and rising for $E$ less than $E^{*}$. But now, when $I$ is small, there will be a demand for inventories, and that will give rise to employment increases, even when $E$ is larger than $E^{*}$. It follows that the curve $d E / d t$ is downward sloping, It is easy to show that in this case, even when the parameters are such that the economy converges to the equilibrium, it may spiral in. Convergence may not be monotonic.

\section{A.3.1. Lagged consumption and discrete time}

Consumption may not depend on income today, but on lagged income. Analyzing such a system requires moving to difference equations. We begin with the simplest version, where the agricultural market clears every period, based on last year's employment and prices:

$$
\beta \alpha=\beta D^{A A}\left(p_{t}, p_{t-1} \alpha\right)+E_{t-1} D^{M A}\left(p_{t-1}, w^{*}\right)
$$

Then this year's employment depends on this year's demand, which depends on last year's income but this year's prices:

$$
H\left(E_{t}\right)=\beta D^{A M}\left(p_{t}, p_{t-1} \alpha\right)+E_{t-1} D^{M M}\left(p t, w^{*}\right)+I
$$

This gives rise to a pair of difference equations giving $\left\{E_{t}, p_{t}\right\}$ as a function of $\left\{E_{t-1}, p_{t-1}\right\}$.

We can simplify the analysis further is we assume that there is a quick response to demand in the agricultural sector, but a lagged demand in the urban sector.

Then

$$
\beta \alpha=\beta D^{A A}\left(p_{t}, p_{t} \alpha\right)+E_{t} D^{M A}\left(p_{t}, w^{*}\right)
$$


can be solved for $p_{t}=Z^{A}\left(E_{t}\right)$, and the result substituted back into the urban employment equation

$$
H\left(E_{t}\right)=\beta D^{A M}\left(Z^{A}\left(E_{t}\right), Z^{A}\left(E_{t-1}\right) \alpha\right)+E_{t-1} D^{M M}\left(Z^{A}\left(E_{t}\right), w^{*}\right)+I
$$

yielding a first order difference equation in Et, with

$$
\frac{d E_{t}}{d E_{t-1}}=\frac{\left.-\left\{\beta D_{y}^{A M} Z^{A^{\prime}}\left(E_{t-1}\right) \alpha\right)+D^{M M}\right\}}{\left[\beta D_{p}^{A M}+E_{t-1} D_{p}^{M M}\right] Z^{A^{\prime}}}
$$

If at $E=E^{*}, d E_{t} / d E_{t-1}<1$, the system is stable.

\section{A.4. Discrete time}

The dynamic system in discrete time corresponding to (A.1) and (A.2) in continuous time is:

$$
\begin{aligned}
& p_{t}=p_{t-1}+D^{A}\left(p_{t-1}, E_{t-1}\right)-\beta \alpha \\
& E_{t}=E_{t-1}+D^{M}\left(p_{t-1}, E_{t-1}\right)-H\left(E_{t-1}\right)
\end{aligned}
$$

Denoting the partial derivative of a function with respect to its lagged argument as follows $y_{x} \equiv \partial y / \partial x_{t-1}$ we can rewrite the same derivatives for $D_{p}^{A}$ etc. with only a slight change of interpretation.

The steady states are the same as above. In order to assess the properties of (each) steady state we must compute the (associated) $2 \times 2$ Jacobian matrix. Each entry of the Jacobian matrix is the derivative of equations (A.3) and (A.2) with respect to the endogenous variables $\left(p_{t-1}\right.$ and $\left.E_{t-1}\right)$, taken in the specified steady state. The Jacobian matrix is:

$$
J=\left(\begin{array}{cc}
1+D_{p}^{A} & D_{E}^{A}>0 \\
D_{p}^{M}>0 & 1+D_{E}^{M}-H_{E}
\end{array}\right)
$$

To study the stability of this system, it is necessary to compute the eigenvalues of the matrix.

Proposition 2. In discrete time, for a system of two difference equations linearized around the steady state, stability requires both eigenvalues to be less than one in absolute value, i.e. $\left|\lambda_{i}\right|<1, i=1,2$. If one eigenvalue is greater than one and the other is smaller than one, i.e. $\left|\lambda_{1}\right|<1<\lambda_{1}$ we have a saddle point.

\section{A.5. An alternative definition of the dynamic system in discrete time}

In Appendix A.4 we propose an alternative definition of the dynamic system in discrete time. We start from the following definitions:

$$
\begin{aligned}
& D^{A}\left(p_{t}, p_{t-1} \alpha, E_{t-1}\right):=\beta D^{A A}\left(p_{t}, p_{t-1} \alpha\right)+E_{t-1} D^{M A}\left(p_{t}, w^{*}\right) \\
& D^{M}\left(p_{t}, p_{t-1} \alpha, E_{t-1}\right):=\beta D^{A M}\left(p_{t}, p_{t-1} \alpha\right)+E_{t-1} D^{M M}\left(p_{t}, w^{*}\right)+I
\end{aligned}
$$

Denoting the partial derivative of a function as $y_{x} \equiv \partial y / \partial x$ we can write:

$$
\begin{aligned}
& D_{p_{t}}^{A}=\beta D_{p_{t}}^{A A}+E_{t-1} D_{p_{t}}^{M A}<0 \\
& D_{p_{t-1}}^{A}=\beta \alpha D_{y}^{A A}>0 \\
& D_{E_{t-1}}^{A}=D^{M A}\left(p_{t}, w^{*}\right)>0 \\
& D_{p_{t}}^{M}=\beta D_{p_{t}}^{A M}+E_{t-1} D_{p_{t}}^{M M}
\end{aligned}
$$

From $D_{p_{t}}^{A M}>0, \quad D_{p_{t}}^{M M}>0$ follows that $D_{p_{t}}^{A M}>0, D_{p_{t}}^{M M}>0$

$$
\begin{aligned}
& D_{p_{t-1}}^{M}=\beta \alpha D_{y}^{A M}>0 \\
& D_{E_{t-1}}^{M}=D^{M M}\left(p_{t}, w^{*}\right)>0
\end{aligned}
$$

From $D^{\mathrm{A}}\left(p_{t}, p_{t-1} \alpha, E_{t-1}\right)-\beta \alpha=0$ we can derive

$$
\begin{aligned}
& p_{t}=Z^{A}\left(p_{t-1}, E_{t-1}\right) \\
& Z_{p_{t-1}}^{A}=-\frac{D_{p_{t-1}}^{A}}{D_{p_{t}}^{A}}=-\frac{\beta \alpha D_{y}^{A A}}{\beta D_{p_{t}}^{A A}+E D_{p_{t}}^{M A}}>0 \\
& Z_{E_{t-1}}^{A}=-\frac{D_{E_{t-1}}^{A}}{D_{p_{t}}^{A}}=-\frac{D^{M A}\left(p_{t}, w^{*}\right)}{\beta D_{p_{t}}^{A A}+E D_{p_{t}}^{M A}}>0
\end{aligned}
$$


Equilibrium in manufacturing occurs when $D^{M}\left(p_{t}, p_{t-1} \alpha, E_{t-1}\right)-H\left(E_{t}\right)=0$ where $p_{t}=Z^{A}\left(p_{t-1}, E_{t-1}\right)$. Hence $D^{M}\left(Z^{A}\left(p_{t-1}, E_{t-1}\right)\right.$, $\left.p_{t-1} \alpha, E_{t-1}\right)-H\left(E_{t}\right)=0$. From this equation we get

$$
\begin{aligned}
& E_{t}=Z^{M}\left(p_{t-1}, E_{t-1}\right) \\
& Z_{p_{t-1}}^{M}=\frac{D_{p_{t}}^{M} Z_{p_{t-1}}^{A}+D_{p_{t-1}}^{M}}{H_{E_{t}}}>0 \\
& Z_{E_{t-1}}^{M}=\frac{D_{p_{t}}^{M} Z_{E_{t-1}}^{A}+D_{E_{t-1}}^{M}}{H_{E_{t}}}>0
\end{aligned}
$$

The steady states are the same as in continuous time. In order to assess the properties of (each) steady state we must compute the (associated) $2 \times 2$ Jacobian matrix. Each entry of the Jacobian matrix is the derivative of equations (A.3) and (A.2) with respect to the endogenous variables $\left(p_{t-1}\right.$ and $\left.E_{t-1}\right)$, taken in the specified steady state. The Jacobian matrix is:

$$
J=\left(\begin{array}{ll}
Z_{p_{t-1}}^{A}>0 & Z_{E_{t-1}}^{A}>0 \\
Z_{p_{t-1}}^{M}>0 & Z_{E_{t-1}}^{M}>0
\end{array}\right)
$$

To study the stability of this system, it is necessary to compute the eigenvalues of the matrix.

The characteristic polynomial is:

$$
J-\lambda I \mid=\left(\begin{array}{cc}
Z_{p_{t-1}}^{A}-\lambda & Z_{E_{t-1}}^{A} \\
Z_{p_{t-1}}^{M} & Z_{E_{t-1}}^{M}-\lambda
\end{array}\right)=\lambda^{2}-\left(Z_{p_{t-1}}^{A}+Z_{E_{t-1}}^{M}\right) \lambda+\left(Z_{p_{t-1}}^{A} Z_{E_{t-1}}^{M}-Z_{E_{t-1}}^{A} Z_{p_{t-1}}^{M}\right)=\lambda^{2}-\operatorname{tr}(J) \lambda+\operatorname{det}(J)
$$

The eigenvalues are given by:

$$
\begin{aligned}
\lambda_{1,2} & =\frac{1}{2}\left(\operatorname{tr}(J) \pm \sqrt{\operatorname{tr}^{2}(J)-4 \operatorname{det}(J)}\right)=\frac{1}{2}\left(\left(Z_{p_{t-1}}^{A}+Z_{E_{t-1}}^{M}\right) \pm \sqrt{\left(Z_{p_{t-1}}^{A}+Z_{E_{t-1}}^{M}\right)^{2}-4\left(Z_{p_{t-1}}^{A} Z_{E_{t-1}}^{M}-Z_{E_{t-1}}^{A} Z_{p_{t-1}}^{M}\right)}\right) \\
& =\frac{1}{2}\left(Z_{p_{t-1}}^{A}+Z_{E_{t-1}}^{M} \pm \sqrt{\left(Z_{p_{t-1}}^{A}\right)^{2}+\left(Z_{E_{t-1}}^{M}\right)^{2}-2 Z_{p_{t-1}}^{A} Z_{E_{t-1}}^{M}-4 Z_{E_{t-1}}^{A} Z_{p_{t-1}}^{M}}\right)
\end{aligned}
$$

\section{References}

Adrian, T., Shin, H., 2008. Liquidity and Leverage. Federal Reserve Bank of New York Staff Report \#398.

Autor, D., Dorn, D., 2011. The Growth of Low-Skill Service Jobs and the Polarization of the U.S. Labor Market. MIT Working Paper, June.

Barro, R., Ursua, J., 2010. Stock-Market Crashes and Depressions. NBER wp \#14760.

Bates, T.W., Kahle, K.M., Stulz, R.M., 2009. Why do U.S. firms hold so much more cash than they used to? Journal of Finance 64 (5), $1985-2021$.

Bell, S., 1940. Productivity, Wages and National Income. The Institute of Economics of the Brookings Institution.

Bernanke, B., Gertler, M., Gilchrist, S., 1999. The financial accelerator in quantitative business cycle framework. In: Taylor, J., Woodford, M. (Eds.), Handbook of Macroeconomics, vol. 1C. North Holland, Amsterdam.

Blum, J., Cameron, R., Barnes, T.G., 1970. The European World: A History, 2nd ed.

Carter, S.B., Gartner, S.S., Haines, M.R., Olmstead, A.L., Sutch, R., Wright, G. (Eds.), 2006. Historical Statistics of the United States, Millennial Edition Online. Cambridge University Press, Cambridge.

Cary Brown, E., 1956. Fiscal policy in the thirties: a reappraisal. The American Economic Review 46 (December (5)), 857-879.

Chandler, L.V., 1970. America's Greatest Depression. Harper and Row, New York.

Demyanyk, Y., Van Hemert, O., 2010. Understanding the Subprime Mortgage Crisis. http://papers.ssrn.com/sol3/papers.cfm?abstract_id=1020396.

Dynan, K.E., Skinner, J., Zeldes, S.P., 2004. Do the rich save more? Journal of Political Economy vol. 112 (2), 397-444, University of Chicago Press.

Easterly, W., Islam, R., Stiglitz, J.E., 2001a. Shaken and stirred: Explaining growth volatility. In: Annual Bank Conference on Development Economics 2000. World Bank, Washington, pp. 191-212.

Easterly, W., Islam, R., Stiglitz, J.E., 2001b. Volatility and macroeconomic paradigms for rich and poor countries. In: Drèze, J.H. (Ed.), Advances in Macroeconomic Theory: Volume 1, IEA Conference vol. 133. Houndsmill, Palgrave, pp. 353-372.

Eggertsson, G.B., and P. Krugman, 2010. Debt, Deleveraging, and the Liquidity Trap: A Fisher-Minsky-Koo Approach, mimeo, Princeton University.

Greenwald, B., Stiglitz, J., 1993. Financial market imperfections and business cycles. Quarterly Journal of Economics 108, $77-114$.

Greenwald, B., Stiglitz, J., 2003. Towards a New Paradigm in Monetary Economics. Cambridge University Press, Cambridge.

Greenwald, B., Stiglitz, J.E., 2006. Helping infant economies grow: foundations of trade policies for developing countries. American Economic Review: AEA Papers and Proceedings 96 (May (2)), 141-146.

Greenwald, B., and J.E. Stiglitz, 2012. Creating a Learning Society: A New Paradigm for Development and Social Progress, working paper, Columbia University. Greenwald, B., Stiglitz, J.E., Weiss, A., 1984. Informational imperfections in the capital markets and macro-economic fluctuations. American Economic Review 74 (1), 194-199.

Hamilton, J., 1987. Monetary factors in the great depression. Journal of Monetary Economics 19 (2), $145-169$.

Krugman, P., 2009. The Return of Depression Economics and the Crisis of 2008. W.W. Norton Company, New York.

Lee, D., Wolpin, K.I., 2006. Intersectoral labor mobility and the growth of the service sector. Econometrica 74 (January (1)), 1-46.

Mulligan, C., 2009. What Caused the Recession of 2008? Hints from Labor Productivity. NBER wp \#14729.

Reinhart, C., Rogoff, K., 2009. This Time is Different: Eight Centuries of Financial Folly. Princeton University Press, Princeton.

Rensberger, S., 1996. The Great Depression. Marshall Cavendish Corporation, New York.

Shiller, R., 2008. The Subprime Solution: How Today's Global Financial Crisis Happened and What to Do about it. Princeton University Press, Princeton.

Stiglitz, J.E., 1999. Beggar-thyself vs. beggar-thy-neighbor policies: the dangers of intellectual incoherence in addressing the global financial crisis. Paper presented to the Annual Meetings of the Southern Economics Association, Baltimore, November 8, 1998. Southern Economic Journal 66 (July (1)), 1-38. 
Stiglitz, J.E., 2010. Freefall: America, Free Markets and the Sinking of the World Economy. W.W. Norton Company, New York.

Stiglitz, J.E., Weiss, A., 1981. Credit rationing in markets with imperfect information. American Economic Review 71 (3), $393-410$.

Swanson, J., Williamson, S., 1972. Estimates of national product and income for the United States economy, 1919-1941. Explorations in Economic History $10,53-73$.

Taylor, J., 2009. Getting Off Track. Hoover Institution Press, Stanford University.

Temin, P., 2010. The Great Recession and the Great Depression. NBER wp \#15645.

Zandi, M., 2011. To Shore Up the Recovery, Help Housing, Special Report, Moody’s Analytics, 25 May 2011. 